\title{
Analyze the Feasibility of Introducing Equestrian Treatment Technology into Qingdao for Treatment
}

\author{
Ziyao chen
}

\author{
No.2 middle school, Qingdao, shandong, China 266000 \\ Chenziyao0322@outlook.com
}

\begin{abstract}
Hippotherapy is a new auxiliary therapy method that physical therapists use the characteristics of equestrian sports to rehabilitate patients with physical or cognitive disorders. Equestrian therapy courses need to be conducted by a team of professionals, including physiotherapists, side care, and horse handlers. According to incomplete statistics, at present, about 45 countries and regions around the world have carried out equestrian therapy courses, and at least 14 regions in mainland China are carrying out or have carried out equestrian therapy courses and related activities. However, there are still no regular equestrian therapy courses in Qingdao. The main purpose of this paper is to explore the feasibility of introducing horsemanship therapy in Qingdao by investigating various influencing factors. It can provide a novel treatment for the majority of disabled people in Qingdao, and contribute to the welfare of the disabled in Qingdao. Through the analysis of relevant literature collection, statistical data and field investigation, it is concluded that Qingdao has certain resources advantages, it has all the necessary conditions for the introduction of equestrian therapy technology. However, it is relatively difficult to provide free services for the disabled. For Qingdao to carry out equestrian therapy courses in the future, it still needs to make preparations and efforts in many aspects.
\end{abstract}

Keywords: Hippotherapy, Exceptional child, autism, special education, physical therapy

\section{INTRODUCTION}

Equestrian therapy is a novelty for most Chinese residents. But around the world, horses have a long history as a therapeutic tool and are thriving in countries around the world. Although equestrian therapy is relatively common in Taiwan, Hong Kong, and other regions, the development of equestrian therapy technology in mainland China is just beginning. Qingdao has about 700,000 disabled people, and there is no equestrian therapy facility in the city. In traditional sensory integration therapy in a hospital or rehabilitation center environment, it is difficult to get patients, especially children, to voluntarily cooperate. In a natural and relaxed environment, patients are more willing to cooperate with treatment. This paper studies the feasibility of introducing equestrian therapy technology into Qingdao. Through the analysis of relevant literature collection, statistical data, and field investigation, this paper explores whether Qingdao has the feasibility of equestrian therapy courses from the factors of the economic environment, social environment, and technical environment. Equestrian therapy courses have been proved to have significant therapeutic effects on the rehabilitation of physical and psychological disorders of the disabled, and the development of equestrian therapy courses has great social benefits.

\section{BACKGROUND}

\subsection{Application in other countries}

Humans have used horses as a therapeutic tool for more than 100 years. Equestrian therapy originated in Europe. 1952 Polio patient Lise Hartl won a silver medal in the Equestrian event at the Olympics. In 1965, Britain's first equestrian treatment center for disabled people opened. Since then, the number of equestrian treatment centers in the UK has mushroomed to nearly 100. During this time, equestrian therapy was introduced to the United States. 1969 The first equestrian therapy center in the United States opened in Michigan. The first International Equestrian Therapy Congress was held in Paris in 1974. In 1980, the International Federation of Disabled Riding was established to promote international cooperation in the field of disabled riding. According to the International Equine Education and Therapy Federation (AISBL), there are currently registered equine therapy institutions 
or individuals from 45 countries and regions, including equine therapy institutions and therapists in mainland China, Taiwan and Hong Kong Special Administrative Region. The United States has become the largest country in the world to offer equestrian therapy courses. According to the International Association of Professional Equestrian Therapists (PATH), there were 849 registered equestrian therapy members in 2018. According to the National Equestrian Therapy Association's 2017 annual report, there were more than 500 equestrian therapy facilities in the UK that year. In addition, the Australian Equestrian Therapy Association, the Canadian Equestrian Therapy Association and the New Zealand Equestrian Therapy Association have more than 80, 100 and at least 56 facilities respectively. Therefore, equestrian therapy courses have been widely developed in the world, while in mainland China, the development of equestrian therapy courses is still in its infancy.

\subsection{Application in China}

In China, the role of equestrian therapy is also being recognized by doctors and scientists. As early as 2006, Beijing Boai Hospital conducted equestrian therapy intervention on children with cerebral palsy in a horse farm in Yanjiao, and conducted a preliminary study on the therapeutic effect. Research results show that horsemanship therapy indeed has a positive effect on limb function rehabilitation[1]. Since then, experts and scholars have been studying and exploring the efficacy of equestrian therapy courses in mainland China, and equestrian therapy institutions have been established in mainland China[2]. Up to now, according to the public information of China's civil affairs departments, the equestrian treatment institutions registered with local civil affairs departments include Chengdu Equestrian Rehabilitation Center for The Disabled, Beijing HOPE Equestrian Rehabilitation Center, and $\mathrm{Xi}$ 'an Sunshine Angel Equestrian Rehabilitation Center for the Disabled in Lianhu District. Although there are not many equestrian therapy services registered with the national civil affairs department, many local riding clubs are already trying to launch their own equestrian therapy courses. According to incomplete statistics, equestrian therapy courses were offered in Beijing, Shanghai, Shenzhen, Nanjing, Jinan, Qingdao, Dalian, Nanning, Haikou, Yinchuan, Wenzhou, Xi 'an, Wuhan, Suzhou, Hangzhou, and Yulin in Mainland China. In addition, the Hong Kong Special Administrative Region was founded in 1975 by the then Governor Of Hong Kong, Mrs. Maclehose. At that time, weekly equestrian therapy activities were held in Sheung Shui Hippo Club Riding School. The Club provided therapy horses and army mules from the British Army. By 1976 nearly 300 riders were participating in equine therapy courses, and the healing society had 14 stallions, 10 ponies, and eight army mules. At that time, the Hong Kong equestrian therapy base was still set up in Sheung Shui Hippo Riding School. As a result of the success of the equestrian therapy course, Mrs. Maclehose received a grant from the Hong Kong Government for the establishment of the Hong Kong Fitness Riding School in Pokfu Lam Hing, which opened in September 1978. In addition, China's Taiwan province also set up a number of equestrian treatment institutions. The history of equestrian therapy courses in Hong Kong and Taiwan is longer than that in mainland China, and for this reason, equestrian therapy courses in Mainland China received strong support from equestrian therapy experts in Hong Kong and Taiwan in the early stage of development.

\section{EQUESTRIAN THERAPY}

As the amplitude and rhythm of the body swing of a horse during walking are similar to the amplitude and rhythm of the pelvic swing of a human walking. Therefore, after a long period of riding training, the patient's range of motion of the pelvis associated joints and related muscle group movement will be improved, thus effectively improving the ability to walk. Other literature reported that equestrian treatment can effectively relieve the phenomenon of increased muscle tone in lower limbs caused by central nervous system diseases by riding[3]. Since horses have a higher body temperature than humans, when a patient rides on a horse, the back of the horse transmits the body temperature to the patient's lower limbs. And because the horse's back structure is relatively wide, the patient will passively abduct the lower limbs during riding the adductor muscle at the same time get passive traction. After 30 to 50 minutes of the equestrian therapy session, the patient developed symptoms of the warm effect of riding and the pull position on the adductor and flexor muscle groups of the lower extremities abnormal muscle tension of lower limbs can be significantly reduced.

In addition to the therapeutic effect on motor function of disabled patients, the therapeutic effect of equestrian therapy courses on cognitive function is also confirmed by much literature. Some scholars have proved that equestrian therapy courses can improve the communication ability and social interaction ability of autistic patients through interactive games[4]. At the same time, it has been confirmed by literature that the learning ability of children with autism spectrum disorder can be significantly improved after receiving equestrian therapy courses[5]. Moreover, equestrian therapy courses can greatly improve the sensory integration of children with autism. In addition, different from other traditional means of rehabilitation therapy, equestrian therapy courses are conducted around horses[6]. Horses are naturally docile animals. Like other animal-assisted therapies, their comfort to people's hearts is also an important factor that makes equestrian therapy courses popular with the majority of patients with disabilities[7]. 
Literature has shown that horsemanship therapy courses can stabilize the emotions of children with social problems, thus correcting their behaviors[8].

\section{CURRENT STATUS OF EQUESTRAIN THERAPY IN CHINA}

According to the City Business Charm Ranking in 2019, cities above the prefecture level in mainland China are divided into first-tier cities and new first-tier cities according to the urban development level index. There are a total of 19 cities, of which only 9 cities have equestrian therapy courses. And, there are a total of 369 cities of other sizes, only 7 of these cities have equestrian therapy courses. The urban development index was statistically correlated with the availability of equestrian therapy courses in the city. The data shows that the higher the urban development index, the higher the proportion of people receiving equine therapy courses, and the more conducive to developing equestrian therapy courses. Therefore, the urban development index may also be a factor influencing whether a city has equestrian therapy courses in reality. Qingdao is a new first-tier city, and a higher urban development index is conducive to Tianjin to carry out equestrian therapy courses

Gross National Product (GDP) is one of the important indicators reflecting local economic conditions, and is the basis for the development of health undertakings and policy making in a region[9]. The study analyzed the GDP of 36 major cities in Mainland China, including four municipalities directly under the Central Government, 22 provincial capitals, five regional capitals and five cities separately listed in the state plan. The average GDP of the 14 cities with equestrian therapy courses was about 1236.73 billion yuan, almost twice the average GDP of the 22 cities without equestrian therapy courses was about 724.64 billion yuan. Therefore, it can be inferred that having a higher level of urban economic development may be a favorable factor to carry out equestrian therapy. However, some cities with low GDP, such as Hainan, Yinchuan and Nanning, have also launched equestrian therapy courses.

According to incomplete statistics, Qingdao has a total of 16 horse farms and 22 professional autism rehabilitation centers. Among them, Zhanyi Horse Farm has tried to to obtain cooperation with a nearby autism rehabilitation center to carry out equestrian treatment activities for autistic patients, but it did not last for a long time due to financial problems.

\section{INTERVIEW}

Based on preliminary data, the results of the interview with the person in charge of mature equestrian therapy techniques in Shanghai are as follows.
Equestrian therapy is currently a relatively unpopular treatment in China, so through cooperation and communication with other units, children with special needs and their parents can better understand this special treatment. The recognition, support and participation of Shanghai Minhang Qizhi School has opened up another new option for the school's students as a therapeutic improvement method and promoted equestrian therapy better. Equestrian rehabilitation activities for children in Shanghai carried out smoothly for many years. During this process, they have maintained benign communication with many experienced volunteers to ensure the safety and quality of the activities.

At present, the main service target is the children of The Head Start School, which is more convenient and simple to communicate with, because it can directly communicate with the school and reduce a large part of the workload. In fact, the volunteer part has always been the biggest unstable factor, because it is most needed and hoped to have stable and persistent people who can come to the site for a long time. However, great progress has been made since 20-21, with more partners who can regularly attend the site.

If the activity can be carried out successfully, it depends on the enthusiasm and selfless dedication of a small number of people in the early stage, including the organizers and the racecourse. And if the activities can be carried out consistently, it is the equestrian rehabilitation activities that will really bring changes to children, parents and volunteer groups in the long term. Witnessing the harvest of everyone's efforts, this is the best positive feedback loop.



Figure 1 a field visit to Shanghai Jinting racecourse

As shown above, equestrian therapy requires a trained physiotherapist, two flankers to protect the special child, a rider to control the horse, and volunteers to accompany the child through activities.

The development of equestrian therapy techniques in Shanghai was greatly supported by Taiwan, where the physical therapists who actually experienced the whole process of equestrian therapy were from Taiwan. If Qingdao wants to develop equestrian therapy technology, 
it can seek support from Hong Kong and Taiwan, where equestrian therapy has a long history.

At present, Qingdao has professional autism rehabilitation centers, but it lacks a stable source of volunteers.

\section{THE NECESSITY AND PROBLEMS OF PROMOTING EQUESTRIAN THERAPY IN QINGDAO}

According to the second National sample survey of persons with disabilities, the number of children with special needs is increasing. In the category of mental disability, autism accounted for $20.83 \%$ of the disability in the group of 0 to 14 years old. Surveillance data from the US Centers for Disease Control and Prevention (CDC) show that: The incidence of autism was 1 in $150(0.67 \%)$ in 2000, and reached 1 in $68(1.47 \%)$ in 2010. In 2018, the latest annual report of 2014 testing data was 1 in 59 $(1.69 \%)$, indicating that the incidence of autism has been on the rise. Conservative estimates put the number of children aged 0 to 14 in China at more than 2 million. Qingdao has nearly 10 million residents. Based on the autism incidence rate of 1.69 percent in China, it is estimated that more than 100,000 people in the city suffer from autism. In 1998, it was reported that there were 310,000 children aged $0-6$ with cerebral palsy in China (prevalence rate was $1.86 \%$ ), and the rate increased by 46,000 every year. According to the World Health Organization, the prevalence of cerebral palsy is $1 \%-5 \%$, and the incidence in China is $1.8 \%-4 \%$. The top three causes of physical disability in $0-14$ years old children were developmental malformation, cerebral palsy and other trauma, accounting for more than $60 \%$ of the total. The above data show that autism and cerebral palsy have become serious global public health problems[10]. And since most people with autism are born with it, people need to ensure that they live a normal life, and need better ways to treat them.

Qingdao has the basic conditions for introducing equestrian therapy, horse farms that can provide treatment sites, professional autism rehabilitation centers, and most families with special children have enough funds to support them to participate in treatment. However, compared with Shanghai and other cities where equestrian treatment technology has matured, Qingdao's conditions are not perfect enough. Qingdao is temporarily unable to provide free treatment services due to economic conditions and other factors. Because the introduction of equestrian therapy in Qingdao has just started, there are not enough trained volunteers. In addition, parents of special children in Qingdao have insufficient understanding of equestrian therapy technology, and need a lot of manpower and material resources to publicize it. In Shanghai, children's equestrian rehabilitation activities have been carried out for many years, and many experienced volunteers have been accumulated, attracting more special groups with needs to participate. In addition, the Shanghai foundation and the selfless dedication of many volunteers solved most of the funding problems, allowing the event to run smoothly for many years.

So, to promote equestrian rehabilitation smoothly in Qingdao, people need to recruit some volunteers of regular attendance, look for one or two suitable racecourses, cooperate with some rehabilitation centers, find personnel support from Hong Kong and Taiwan, the most important thing is to seek financial aid from some larger and stable foundations. Also, there is not enough publicity for equestrian therapy in Qingdao.

\section{CONCLUSION}

To sum up, although Qingdao initially has many advantages to carry out equestrian therapy courses in the early stage, due to the immature objective conditions, it still needs to do a lot of preparatory work to establish the first equestrian therapy institution in Qingdao and carry out equestrian therapy courses. The conclusion of the study is that Qingdao is not fully equipped to carry out equestrian therapy courses at present, but with the existing resource advantages and social progress, Qingdao will certainly have its own public welfare charity organization specializing in providing equestrian therapy courses for the disabled in the future.

The research will continue to study and discuss this, and create favorable conditions for the establishment of institutions and the development of courses in the future. Although the research is still a very superficial investigation, the deficiencies of this research will be further explored in the future research. Finally, all the restrictive elements of equestrian therapy courses were found and dealt with and solved, providing theoretical reference for those who intend to establish equestrian therapy institutions and carry out equestrian therapy courses.

\section{ACKNOWLEDGMENT}

Firstly, I would like to show my deepest gratitude to my thesis advisor and professor, who have provided me with valuable guidance in every stage of the writing of this thesis. Further, I would like to thank all my friends and parents for their encouragement and support. Without all their enlightening instruction and impressive kindness, I could not have completed my thesis.

\section{REFERENCES}

[1] Wu Weihong, Li Xin. Equestrian therapy for disabled children [C]. The fifth National Academic Conference of Rehabilitation Therapy of Chinese Rehabilitation Association

[2] Journal of Applied Physics, 2006: 157-160. 
Wang Feng, Xia Yunjian. Feasibility analysis of equestrian rehabilitation therapy in China [C]. 2015 National Sports Health Rehabilitation Academic Conference, 2016:182-183.

[3] R. Martın-Valero, J. Vega-Ballon, V. Perez-Cabezas. Benefits of hippotherapy in children with cerebral palsy: A narrative review[J]. European journal of paediatric neurology, 2018(22):

1150-1160.

[4] Gao Yan, Hong Qi, Luo Xiaoxing et al. Chinese Journal of Maternal and Child Health Research, 2018, 029(007): 837-841.

[5] Beth L. Macauley, Karla M. Gutierrez. The effectiveness of hippotherapy for children with

language-learning disabilities[J]. ProQuest Education Journals, 2004, 25(4): 205-217.

[6] Yang Xiaoke. Research on the influence of physical education intervention with turn-based teaching method on sensory integration function of autistic children [D]. Jilin: Jilin

University, 2018.

[7] Chen Quanyin, Tang Yanqiu, Tang Jing et al. A review of studies on the improvement of social skills of children with autism by animal-assisted therapy. Modern Special Education, 2018, 000(014): 29-36.

[8] Zhang Baoguo, WANG Xiaodi, TAO Yu et al. Research progress of horseback riding therapy in the rehabilitation of motor function and psychological and social function in children with disabilities [J]. Chinese Journal of Physical Medicine and Rehabilitation, 2014, 36(6): 490-493.

[9] Man X W. Research on the relationship between health expenditure and GDP based on health output [D]. Beijing: Beijing University of Chinese Medicine, 2015.

[10] Shi Mengni, Li Shuping, Tao Jiang Equestrian sports intervention for children with special needs (autism and cerebral palsy) 